\section{Angebote entwickeln und vermarkten}

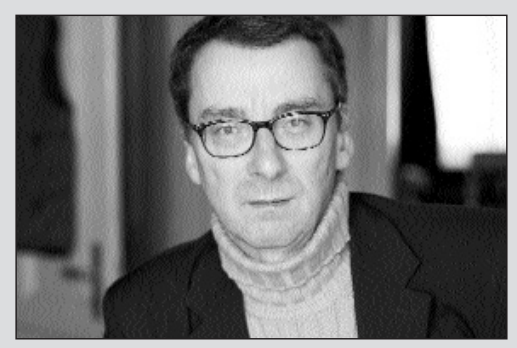

Wenn die Mittel knapp werden, gilt der erste - und oft auch letzte Gedanke dem Sparen. Die Frage, wie zusätzliche Ressourcen - Geld, ehrenamtliches Engagement, Spenden-erschlossen werden können, wird oft erst gar nicht gestellt. Doch viele soziale Organisationen könnten mit Kreativität und durch das Gespräch mit ihren Nutzern neue Produkte und innovative Dienstleistungen entwickeln und vermarkten.

Klaus-Dieter Liedke zeigt in seinem Beitrag in diesem Heft, wie das aussehen kann. So können mit einer Marktfeldanalyse die gegenwärtigen Verhältnisse der Organisation dem Entwicklungspotenzial neuer Hilfeleistungen gegenübergestellt werden: Man gewinnt so einen Überblick über das gesamte Handlungsfeld des Unternehmens mit allen denkbaren Möglichkeiten einer zusätzlichen Betätigung (Seite 9).

In wenigen Monaten, am 1. Januar 2008, tritt der uneingeschränkte Rechtsanspruch auf ein Persönliches Budget in Kraft. Menschen mit Ansprüchen an die Sozialleistungsträger können dann anstelle der bisherigen Sachleistung ohne Vorbehalt bares Geld verlangen, um sich die erforderlichen Hilfen selbst zu finanzieren. Für soziale Dienstleister ist dies eine gute - und für manche sogar überlebensnotwendige - Gelegenheit, ihre bisherigen Komplexleistungen aufzuschnüren und als Einzelangebote zu vermarkten.

Die »ambulante dienste e. $V$. « in Berlin haben sich mit ihrem Assistenzdienst für behinderte Menschen frühzeitig auf diese Situation eingestellt und im Hinblick auf das Persönlichen Budget das »Splitting-Modell « entwickelt (Seite 21). Dabei organisiert der Budgetnehmer eine bestimmte Zeit, beispielsweise das Wochenende, seinen Assistenzbedarf selbst durch Freunde, Nachbarn oder andere Helfer. Die restliche Zeit sowie eventuelle Ausfälle der privaten Helfer werden, vertraglich geregelt, durch die angestellten Assistenzkräfte der »ambulanten dienste " abgedeckt - ein Beispiel dafür, wie die eigene Kompetenz neu vermarktet werden kann.

Gerhard Pfannendörfer - Chefredaktion -

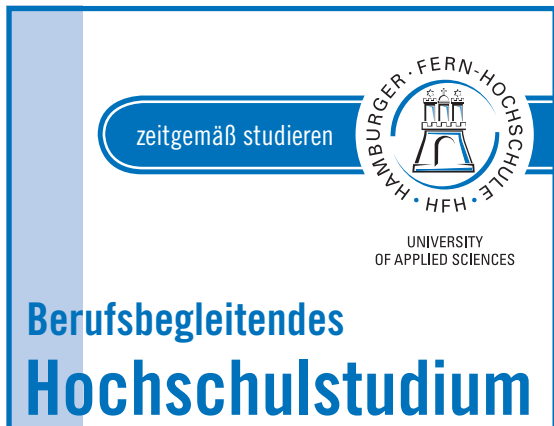

Über 6.000 Studierende - Ausdruck des Vertrauens in das Studienkonzept der staatlich anerkannten

HFH · Hamburger Fern-Hochschule

Unser bewährtes Fernstudienkonzept verbindet individuelles Lernen zu Hause mit dem Angebot regelmäßiger Präsenzphasen in unseren 39 regionalen Studienzentren.

Wir informieren Sie gern ausführlich über unsere berufsbegleitenden Studiengänge:

\section{NEU Gesundheits- und Sozialmanagement}

mit dem Abschluss Bachelor of Arts (B.A.)

\section{Pflegemanagement}

mit dem Abschluss Diplom-Pflegewirt/in (FH)

Der Hochschulzugang ist auch für Berufstätige ohne Abitur möglich.

Weitere Studienangebote der HFH mit Bachelor-Abschluss:

- Betriebswirtschaft

- Wirtschaftsingenieurwesen

- Wirtschaftsrecht

Fordern Sie einfach kostenlos unsere Studienführer an oder besuchen Sie eine unserer Informationsveranstaltungen. Termine finden Sie im Internet.

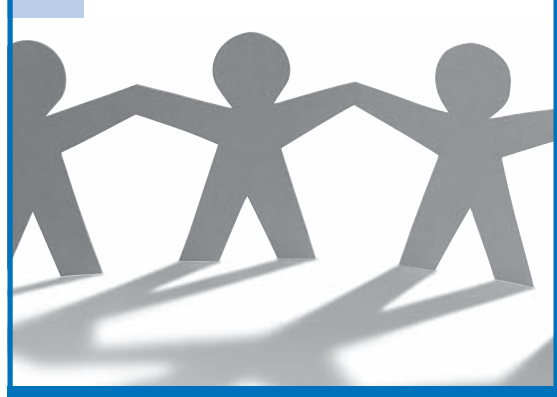

www.hamburger-fh.de info@hamburger-fh.de Infoline: 01805235210 Mo. - do. 8 - 19, fr. 8 - 18 Uhr (EUR 0,14/Min.) 